
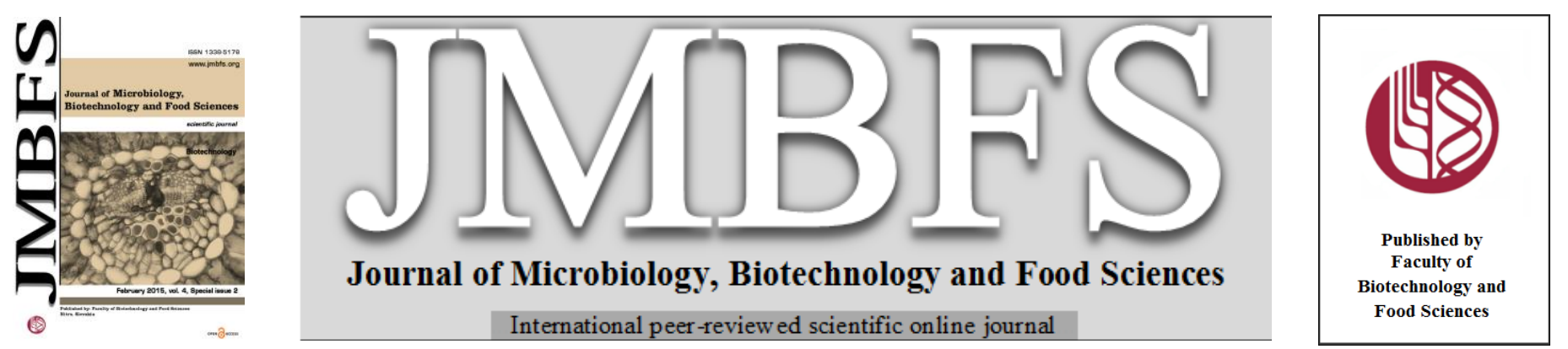

\title{
BIS(2-ETHYLHEXYL) PHTALATE AFFECTS SPERMATOZOA MOTILITY DURING SHORT-TERM IN VITRO CULTIVATION
}

\author{
Jana Lukáčová*, Tomáš Jambor, Zuzana Kňažická, Eva Tvrdá, Norbert Lukáč
}

Address(es): Ing. Jana Lukáčová

Slovak University of Agriculture in Nitra, Faculty of Biotechnology and Food Sciences, Department of Animal Physiology, Tr. A. Hlinku 2, 949 76 Nitra, Slovak republic, phone number: +421-37-6414288

\section{ARTICLE INFO}

Received 2. 12. 2014

Revised 9. 12. 2014

Accepted 16. 12. 2014

Published 2. 2. 2015

Regular article open 2 access

\begin{abstract}
Bis(2-ethylhexyl) phthalate is ubiquitous in the environment as a results of its widespread manufacture and use, as well as their high concentration in plastics and ability to migrate from them into the air, water and ground, and then enters foodstuffs. The present study evaluated the effects of BEHP at the doses $1,10,100$ and $200 \mu \mathrm{g} / \mathrm{mL}$ on the motility of bovine spermatozoa during short-term in vitro cultivation. The CASA system with SpermVision ${ }^{\mathrm{TM}}$ program was used to determine the spermatozoa motility. The initial evaluation showed the decrease of motility with significant differences $(P<0.05)$ and $(P<0.001)$ at the doses $1 ; 100$ and $200 \mu \mathrm{g} / \mathrm{mL}$ of $\mathrm{BEHP}$ in comparison to the control. At this time, a slightly increase of motility was noted at the dose $10 \mu \mathrm{g} / \mathrm{mL}$, but this increase was not significant $(P>0.05)$. Also, the doses $>100 \mu \mathrm{g} / \mathrm{mL}$ of BEHP decreased motility significantly $(P<0.001)$ after $2 \mathrm{~h}$ of in vitro cultivation. At the dose $1 \mu \mathrm{g} / \mathrm{mL}$ was observed the increase of motility and the decrease of motility at the dose $10 \mu \mathrm{g} / \mathrm{mL}$. After $4 \mathrm{~h}$ of cultivation the decrease of spermatozoa motility $(P<0.001)$ was noted in all experimental groups containing BEHP. Significant differences $(P<0.001)$ were found out only at the highest doses of BEHP. The dose $200 \mu \mathrm{g} / \mathrm{mL}$ markedly significantly decreased $(P<0.001)$ motility in comparison to the control after $6 \mathrm{~h}$ of cultivation. In conclusion, the data obtained from our experiments suggest the damaging effects especially of the highest doses of BEHP on spermatozoa motility during short-term in vitro cultivation.
\end{abstract}

Keywords: bis(2-ethylhexyl) phthalate, bovine spermatozoa, motility, CASA system

\section{INTRODUCTION}

BEHP, which is an abbreviation for bis(2-ethylhexyl) phthalate (or DEHP - di(2ethylhexyl) phthalate ), is a liquid of low volatility, widely used as a plasticizer in flexible polyvinyl chloride products (PVC). Plastics may contain from $1-40 \%$ $\mathrm{BEPH}$ by weight and are used in consumer products such as artificial leather, waterproof clothing, footwear, upholstery, foor tiles, various types of furnishing, industrial tubing, wires and cables, tablecloths, shower curtains, food packing materials, children's toys and a variety medical devices. BEPH is also used as a hydraulic fluid and dieletric fluids (ATSDR, 1989; Tanaka, 2002). Other uses are in rubbing alcohol, liquid detergents, decorative inks, industrial lubricating oils and deforming agents during paper and paperboard manufacture (Environmental Protection Agency, 1998).

BEHP can break down in the presence of other chemicals to produce mono(2ethylhexyl)phthalate (MEHP) and 2-ethylhexanol. Many of the properties of MEHP are like those of BEHP, and therefore its fate in the environment is similar. In the presence of oxygen, BEHP in water and soil can be broken down by microorganisms to carbon dioxide and other simple chemicals. BEHP does not break down very easily when deep in the soil or at the bottom of lakes or rivers where there is little oxygen. It can be found in small amounts in fish and other animals, and some uptake by plants has been reported. Humans can be exposed to BEHP through air, water, or skin contact with plastics that have BEHP in them. Food may also contain BEHP, but it is not certain how much (ATSDR, 2002).

BEHP is known reproductive toxicant in animals, which reduce fertility and induce testicular athropy (Albro, 1987) due to its endocrine disruptirng activities, which is capable of perturbing the reproducitve process by mimicking or antaonizing steroid action (Sharpe, 2001). The endocrine disrupting potential of BEHP is directly associated with the synthesis of sex hormones. BEHP alters the expression of genes associated with testis development and steroid hormones synthesis (Albro, 1987; Shultz et al., 2001; Wong and Gill, 2002). The Sertoli cells are the primary site of phtalate-induced testicular toxicity and the alterations of these cells lead to distuption of spermatogenesis and degeneration of spermatocytes and spermatids (Agarwal et al., 1986; Park et al., 2002).

The objective of our study was to analyze the effect of various concentrations of bis(2-ethylhexyl) phthalate (BEHP) dissolved in $1 \%$ ethanol on bovine spermatozoa motility during several time periods.

\section{MATERIAL AND METHODS}

\section{Semen Samples and In Vitro Culture}

Biological material was obtained from 4 adult breeding bulls (Slovak Biological Services, Lužianky - Nitra, Slovak Republic). The samples had to accomplish the basic criteria given for the corresponding breed. The semen was obtained on a regular collection schedule using an artificial vagina. After collecting the samples were stored in the laboratory at room temperature $\left(22-25^{\circ} \mathrm{C}\right)$. Each sample was diluted in physiological saline solution (sodium chloride $0.9 \%$, w/v, Bieffe Medital, Italia), using a dilution ratio of 1:40, depending on the original spermatozoa concentration. Spermatozoa were incubated with various concentrations of bis(2-ethylhexyl) phthalate (BEHP; Cat. \# 80030, Fluka, Buchs, Switzerland) dissolved in 1\% ethanol (Cat. \# 100971.1000, Merck KGaA, Darmstadt, Germany) - group 1; 10; 100 and $200 \mu \mathrm{g} / \mathrm{mL}$ of BEHP in 96-well cell culture plates $(200 \mu \mathrm{L} /$ per well) (Cat. \# 2103.4210, BRANDTech Scientific, Essex, UK) at room temperature $\left(22-25^{\circ} \mathrm{C}\right) .1 \%$ ethanol was used as the negative control (N Ctrl). The control (Ctrl) group (medium without BEHP) was compared to the experimental groups (media exposed to various concentrations of BEHP).

\section{CASA system}

Spermatozoa motility was used as an indicator of semen quality during evaluating of BEHP impact on spermatozoa. The motility analysis was carried out using a CASA (Computer Assisted Semen Analyzer) system SpermVision ${ }^{\mathrm{TM}}$ program (MiniTüb, Tiefenbach, Germany) with the Olympus BX 51 microscope (Olympus, Tokyo, Japan) at cultivation times 0 h, $2 \mathrm{~h}, 4 \mathrm{~h}$ and $6 \mathrm{~h}$. Each sample was placed into the Makler Counting Chamber (deph $10 \mu \mathrm{m}$, SefiMedical Instruments, Haifa, Izrael) and percentage of motile spermatozoa (motility $>5 \mu \mathrm{m} / \mathrm{s}$; MOT) was evaluated. This study was performed in eight replicates at each concentration. At least 1000 spermatozoa were analyzed in each sample.

\section{Statistical analysis}


Obtained data were statistically analyzed using GraphPad Prism 3.02 (GraphPad Software Incorporated, San Diego, California, USA). Descriptive statistical characteristics (mean, minimum, maximum, standard deviation and coefficient of variation) were evaluated. One-way analysis of variance (ANOVA) and the Dunnett's multiple comparison test were used for statistical evaluations. The level of significance was set at $* * *(P<0.001) ; * *(P<0.01)$ and $*(P<0.05)$

\section{RESULTS AND DISCUSSION}

\section{Evaluation of bovine spermatozoa motility after BEHP treatment}

The initial evaluation $(0 \mathrm{~h})$ showed the decrease of spermatozoa motility with significant differences $(P<0.05)$ and $(P<0.001)$ at the doses $1 ; 100$ and 200 $\mu \mathrm{g} / \mathrm{mL}$ of bis(2-ethylhexyl) phthalate in comparison to the control group without BEHP $(86.98 \% ; 83.89 \%$ and $78.59 \%$ versus $91.20 \%)$. At this time, a slightly increase of motility was noted at the dose $10 \mu \mathrm{g} / \mathrm{mL}$ compared to the control group (92.41\% versus $91.20 \%)$, but this increase was not significant $(P>0.05)$ No significant difference was found between negative control group (N Ctrl) and control group (Ctrl) during all time periods. Results are shown in the table 1 and figures 1-4. The highest concentrations of BEHP $(100$ and $200 \mu \mathrm{g} / \mathrm{mL})$ decreased spermatozoa motility significantly $(P<0.001)$ also after $2 \mathrm{~h}$ of in vitro cultivation (76.73\% and $76.50 \%$ in comparison to $84.78 \%$ ). At the dose $1 \mu \mathrm{g} / \mathrm{mL}$ of bis $(2-$ ethylhexyl) phthalate was observed the increase of motility and at the dose 10 $\mu \mathrm{g} / \mathrm{mL}$ of BEHP the decrease of motility, but these values were not significant $(P>0.05)(81.36 \%$ and $85.48 \%$ versus $84.78 \%)$. Aso, after $4 \mathrm{~h}$ of in vitro cultivation the decrease of bovine spermatozoa motility $(P<0.001)$ was noted in all experimental groups containing BEHP. Significant differences $(P<0.001)$ were found out between the highest doses of BEHP and control group $(69.87 \%$ and $67.22 \%$ versus $75.43 \%$ ). The dose $200 \mu \mathrm{g} / \mathrm{mL}$ of BEHP markedly significantly decreased $(P<0.001)$ motility in comparison to the control group after $6 \mathrm{~h}$ of cultivation ( $47.29 \%$ versus $71.66 \%)$.

\begin{tabular}{|c|c|c|c|c|c|c|}
\hline \multirow[t]{2}{*}{ Groups } & \multirow[t]{2}{*}{ Ctrl } & \multirow[t]{2}{*}{ N Ctrl } & 1 & 10 & 100 & 200 \\
\hline & & & \multicolumn{4}{|c|}{$\mu \mathrm{g} / \mathrm{mL}$ of BEHP } \\
\hline \multicolumn{7}{|c|}{ Time 0} \\
\hline $\mathbf{x}$ & 91.20 & 89.34 & $86.98^{\mathrm{C}}$ & 92.41 & $83.89^{\mathrm{A}}$ & $78.59^{A}$ \\
\hline minimum & 85.48 & 80.76 & 78.89 & 84.74 & 71.76 & 67.46 \\
\hline maximum & 98.61 & 95.58 & 91.75 & 97.18 & 90.38 & 91.89 \\
\hline S.D. & 3.02 & 3.84 & 3.57 & 3.22 & 4.99 & 6.76 \\
\hline $\mathrm{CV}$ & 3.31 & 4.30 & 4.10 & 3.48 & 5.95 & 8.60 \\
\hline \multicolumn{7}{|c|}{ Time 2} \\
\hline $\mathbf{x}$ & 84.78 & 86.62 & 81.36 & 85.48 & $76.73^{\mathrm{A}}$ & $76.50^{A}$ \\
\hline minimum & 78.72 & 77.14 & 67.44 & 77.08 & 69.44 & 55.17 \\
\hline maximum & 91.34 & 91.66 & 89.04 & 91.70 & 87.50 & 85.36 \\
\hline S.D. & 3.51 & 4.15 & 5.23 & 4.04 & 5.56 & 9.75 \\
\hline $\mathrm{CV}$ & 4.15 & 4.79 & 6.43 & 4.72 & 7.24 & 12.74 \\
\hline \multicolumn{7}{|c|}{ Time 4} \\
\hline $\mathbf{x}$ & 75.43 & 74.01 & 73.90 & 71.30 & $69.87^{\mathrm{C}}$ & $67.22^{A}$ \\
\hline minimum & 64.58 & 66.00 & 63.79 & 56.52 & 62.96 & 42.85 \\
\hline maximum & 82.69 & 82.60 & 81.57 & 81.08 & 76.05 & 78.94 \\
\hline S.D. & 4.59 & 4.76 & 5.15 & 6.52 & 4.273 & 8.11 \\
\hline CV & 6.09 & 6.43 & 6.97 & 9.14 & 6.12 & 12.06 \\
\hline \multicolumn{7}{|c|}{ Time 6} \\
\hline $\mathbf{x}$ & 71.66 & 71.61 & 71.71 & 70.93 & 67.14 & $47.29^{A}$ \\
\hline minimum & 62.50 & 64.00 & 75.00 & 69.38 & 68.88 & 35.71 \\
\hline maximum & 78.44 & 77.27 & 86.95 & 77.80 & 84.74 & 67.27 \\
\hline S.D. & 4.99 & 3.90 & 3.57 & 5.86 & 5.55 & 8.51 \\
\hline $\mathrm{CV}$ & 6.96 & 5.45 & 4.38 & 7.24 & 7.20 & 18.00 \\
\hline
\end{tabular}

Legend: Ctrl - control group, $\mathrm{N}$ Ctrl - negative control group, $\mathrm{x}$ - mean, SD - standard deviation, CV - coefficient of variation (\%) ${ }^{\mathrm{A}} P<0.001 ;{ }^{\mathrm{B}} P<0.01 ;{ }^{\mathrm{C}} P<0.05$

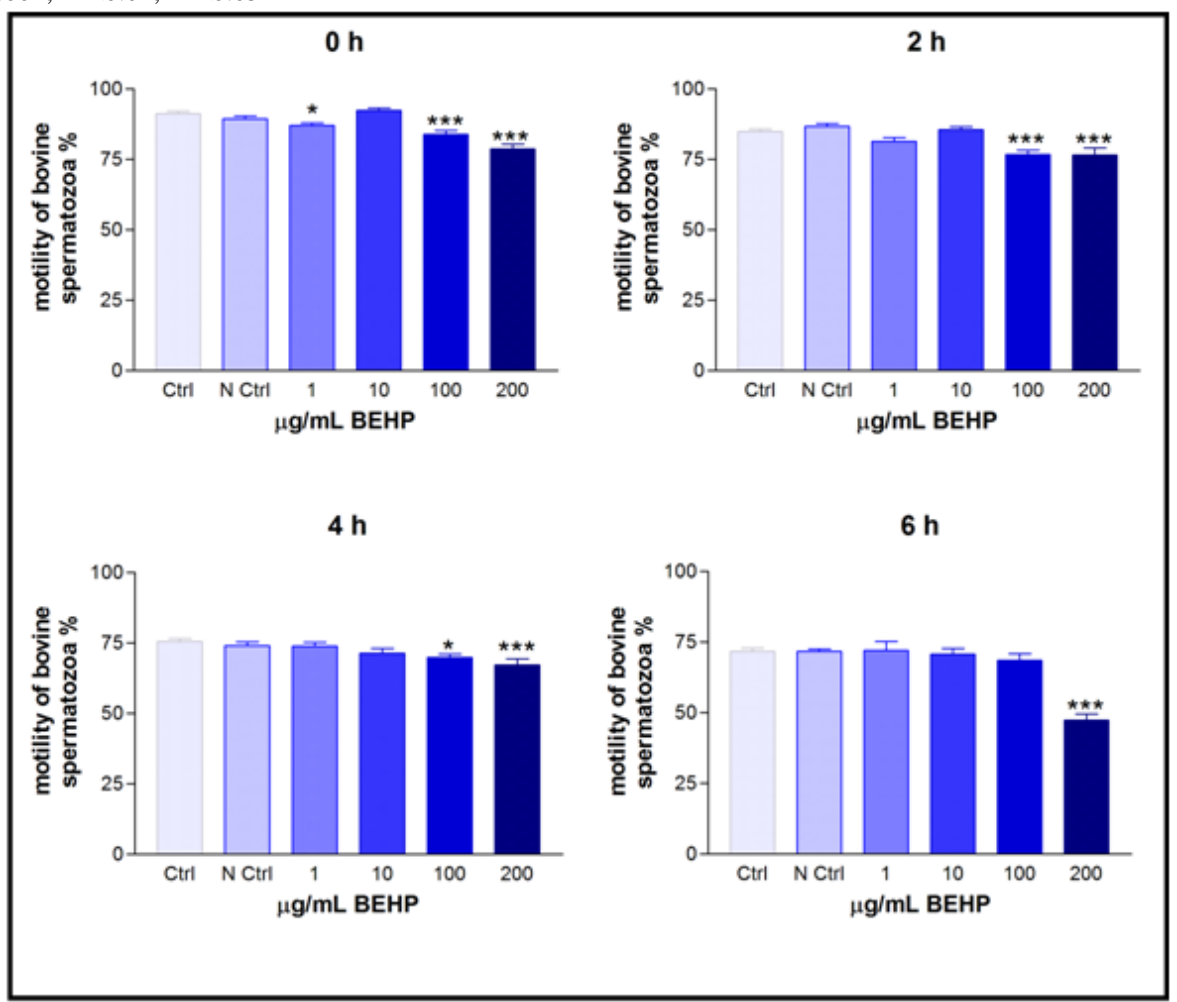

Figures 1-4 Effect of various concentrations of bis(2-ethylhexyl) phthalate dissolved in $1 \%$ ethanol on bovine spermatozoa motility (\%) at 0,2 , 4 and 6 h of in vitro cultivation. The level of significance was set at ${ }^{* * * *} P<0.001 ;{ }^{* *} P<0.01 ;{ }^{*} P<0.05$. 
Toxicological studies have consitently shown that phtalates such as bis(2ethylhexyl) phthalate are reproductive and developmental toxicants. Studies in rodents exposed to doses in excess of $100 \mathrm{mg} / \mathrm{kg} / \mathrm{day}$ BEHP clearly indicate that the testes are a primary target tissue, resulting in decreased testicular weights and tubular atrophy (Parmar et al., 1995; Saitoh et al., 1997; Dorostghoal et al., 2012). Weights of the seminal vesicles, epididymis, and prostate gland in rats and mice are also reduced by oral exposure BEHP (Gray and Butterworth, 1980; Lamb et al., 1987). Within the testis, Sertoli cells appear to be the target of BEHP toxicity (Sjoberg et al., 1986; Saitoh et al., 1997; Li et al., 2000).

The effects of BEHP on spermatogenesis were indicated by the appearance of damaged spermatogenic cells and abnormal sperm in rats exposed to $2000 \mathrm{mg}$ $\mathrm{BEHP} / \mathrm{kg} /$ day in the diet for 15 days (Parmar et al., 1986)

In our present study, we evaluated the impact of BEHP at the doses 1, 10, 100 and $200 \mu \mathrm{g} / \mathrm{mL}$ on the bovine spermatozoa motility during short-term in vitro cultivation. Our findings showed that mainly high concentrations 100 and 200 $\mu \mathrm{g} / \mathrm{mL}$ of BEHP significantly negatively affect the spermatozoa motility. On the other hand, the concentrations lower than $10 \mu \mathrm{g} / \mathrm{mL}$ of BEHP seem to have a positive effect on motility until $4 \mathrm{~h}$ of in vitro cultivation.

With chronic exposures to BEHP, the testicular damage persists, as was demonstrated by inhibition of spermatogenesis and atrophy seen in rats after lifetime exposure to $600-2000 \mathrm{mg} / \mathrm{kg} / \mathrm{day}$ (David et al., 2000). Fertility was also reduced in male mice that were exposed to BEHP over a period of 126 days in dietary doses of $140 \mathrm{mg} / \mathrm{kg} / \mathrm{day}$ indicating that BEHP affected the process of spermatogenesis. The numbers of motile sperm and the sperm concentration were decreased significantly and there was an increase in the number of abnormal sperm (Lamb et al., 1987). Alterations in Sertoli cells consisting of disruption of the ectoplasmic specializations, including the disappearance of actin bundles in the cells as early as 3 hours after a single gavage dose of $2800 \mathrm{mg} \mathrm{BEHP} / \mathrm{kg}$ in rats were described by Saitoh $\boldsymbol{e t}$ al., 1997. Proliferation of Sertoli cells was reduced and morphology of germ cells was altered (gonocytes were enlarged and multinucleated) 24 hours after administration of a single gavage dose of 100 $\mathrm{mg} / \mathrm{kg}$ to 3-day-old rat pups (Li et al., 2000).

Very interesting finding is that the age at first exposure to BEHP appears to have a clear influence on the degree and permanence of testicular damage (Gray and Butterworth, 1980; Sjoberg et al., 1986; Dostal et al., 1988). Tubular structure and spermatogenesis are more affected by prepubertal acute exposure than by postpubertal acute exposure. When newborn rats were exposed to BEHP for 5 day periods at different time intervals between postpartum days 6 and 86, the degree of testicular damage, as manifest in tubular structure, Sertoli cell nuclei and spermatocytes, decreased as the age of first exposure increased (Dostal $\boldsymbol{e t} \boldsymbol{a l}$., 1988; Sjoberg et al., 1986). Also, several developmental studies have been shown that BEHP can affect spermatogenesis in adults and impair development of fetal male rats caused to deformities such as undescended testes, hypospadias, epididymal agenesis and a reduction of the anogenital distance (Gray $\boldsymbol{e t}$ al., 1997; Imajima et al., 1997; Mylchreest et al., 1999; Shono et al., 2000).

\section{CONCLUSION}

The male reproductive toxicity of bis(2-ethylhexyl) phthalate has been extensively studied in laboratory animals including rats, mice, hamsters, and ferrets. Depending on the dose, duration of exposure, and age of animals, BEHP causes reduced fertility, decreased weights of male reproductive organs such as the testes, seminal vesicles, epididymis, and prostate gland, and histopathological changes in the testes of juvenile and also adult rats. BEHP also has been reported to cause developmental toxicity, including intrauterine death, developmental delay, and structural malformations and variations. In our study, we investigated the impact of BEHP treatment on the bovine spermatozoa motility during shortterm in vitro cultivation $(6 \mathrm{~h})$. The obtained data confirmed that mainly high concentrations 100 and $200 \mu \mathrm{g} / \mathrm{mL}$ of BEHP negatively affect the spermatozoa motility. On the other hand, the concentrations lower than $10 \mu \mathrm{g} / \mathrm{mL}$ seem to have a positive influence on spermatozoa motility until $4 \mathrm{~h}$ of in vitro cultivation. Acknowledgments: This study was supported by the European Community under the Project no. 26220220180: Building Research Centre „AgroBioTech" and the Scientific Grant Agency of the Ministry of Education of the Slovak Republic VEGA, Project no. 1/0857/14.

\section{REFERENCES}

AGARWAL, D.K., EUSTIS, S., LAMB, L.C., REEL, J.R., KLUWE, W.M. 1986. Effects of di(2-ethylhexyl) phtalate on the gonadal pathophysiology, sperm morphology, and reproductive performance of male rats. Environmental Health Perspectives, 65, 343-350. http://dx.doi.org/10.1289/ehp.8665343

ALBRO, P.W. 1987. The biochemical toxicology of di(2-ethylhexyl) and related phthalates: Testicular athropy and hepatocarcinogenesis. Reviews of Biochemical Toxicology, 8, 73-119.

ATSDR, 1989. Toxicological profile for di(2-ethylhexyl)phthalate. Agency for Toxic Substances and Disease Registry, United States Public Health Service, Atlanta (GA). http://dx.doi.org/10.1201/9781420061888_ch70
ATSDR, 2002. Toxicological Profile for DI(2-Ethylhexyl)Phthalate Agency for Toxic Substances and Disease Registry, United States Public Health Service, Atlanta (GA). http://dx.doi.org/10.1201/9781420061888_ch70

DAVID, R.M. 2000. Exposure to phthalate esters. Environental Health Perspectives, 108, A440. http://dx.doi.org/10.2307/3435032

DOROSTGHOAL, M., MOAZEDI, A.A., ZARDKAF, A. 2012. Long-term effects of maternal exposure to Di (2-ethylhexyl) Phthalate on sperm and testicular parameters in Wistar rats offspring. Iranian Journal of Reproductive Medicine, 10 (1), 7-14.

DOSTAL, L.A., CHAPIN, R.E., STEFANSKI, S.A., HARRIS, M.W., SCHWETZ, B.A. 1988. Testicular toxicity and reduced Sertoli cell numbers in neonatal rats by di(2-ethylhexyl)phthalate and the recovery of fertility as adults. Toxicology and Applied Pharmacology, 95, 104-21. http://dx.doi.org/10.1016/s0041-008x(88)80012-7

Envirinmental Protection Agency, 1998. Technical Factsheet on: Di(2ethylhehyl)Phthalate (DEPH). Office of Ground Water and Drinking water, Washington $D C$.

GRAY, L.E. Jr, OSTBY, J., FURR, J., PRICE, M., VEERAMACHANENI, D.N., PARKS, L. 2000. Perinatal exposure to the phthalates DEHP, BBP, and DINP, but not DEP, DMP, or DOTP, alters sexual differentiation of the male rat. Toxicological Science, 58, 350-365. http://dx.doi.org/10.1093/toxsci/58.2.350

GRAY, T.J., BUTTERWORTH, K.R. 1980. Testicular atrophy produced by phthalate esters. Archives of Toxicology Supplement, 4, 452-455. http://dx.doi.org/10.1007/978-3-642-67729-8_106

IMAJIMA, T., SHONO T., ZAKARIA, O., SUITA, S. 1997. Prenatal Phthalate causes cryptorchidism postnatally by inducing transabdominal ascent of the testis in fetal rats. Journal of Pediatric Surgery, 32, 18-21. http://dx.doi.org/10.1016/S0022-3468(97)90083-X

LAMB, J.C. t., CHAPIN, R.E., TEAUE, J., LAWTON, A.D., REEL, J.R. 1987. Reproductive effects of four phthalic acid esters in the mouse. Toxicology and Applied Pharmacology, 88, 255-269. http://dx.doi.org/10.1016/0041008x(87)90011-1

LI, L.H., JESTER, W.F.J., LASLETT, A.L., ORTH, J.M. 2000. A single dose of Di-(2-ethylhexyl) phthalate in neonatal rats alters gonocytes, reduces sertoli cell proliferation, and decreases cyclin D2 expression. Toxicology and Applied Pharmacology, 166, 222-229. http://dx.doi.org/10.1006/taap.2000.8972

MYLCHREEST, E., SAR, M., CATTLEY, R.C., FOSTER, P.M.D. 1999 Disruption of androgen-regulated male reproductive development by Di (n-butyl) Phthalate during late gestation in rats is different from flutamide. Toxicology and Applied Pharmacology, 156. 81-95. http://dx.doi.org/10.1006/taap.1999.8643

PARK, J.D., SULTAN, S.M.H., KLAASSEN, C.D. 2002. Testicular toxicity of di-(2-ethylhexyl)phtalate in young Spraque.Dawley rats. Toxicology, 171, 105115. http://dx.doi.org /10.1016/S0300-483X(01)00567-4

PARMAR, D., SRIVASTAVA, S.P., SETH, P.K. 1986. Effects of di(2 ethylhexyl)phthalate (DEHP) on spermatogenesisi in adult rats. Toxicology, 42, 47-55. http://dx.doi.org/10.1016/0300-483x(86)90091-0

PARMAR, D., SRIVASTAVA, S.P., SINGH, G.B. 1995. Testicular toxicity of di(2-ethylhexyl)phthalate in developing rats. Veterinary and human toxicology, 37(4), 310-313.

SAITOH, Y., USUMI, K., NAGATA, T., MARUMO, H., IMAI, K., KATOH, M. 1997. Early Changes in the Rat Testis Induced by Di-(2-Ethylhexyl) Phthalate and 2,5-Hexanedione: Ultrastructure and Lanthanum Trace Study. Journal of Toxicologic Pathology, 10, 51-57. http://dx.doi.org/10.1293/tox.10.51

SHARPE, R.M. 2001. Hormones and testis development and the possible adverse effects of environmental chemicals. Toxicology Letters, 120, 221-232. http://dx.doi.org/10.1016/s0378-4274(01)00298-3

SHONO T., KAI, H., SUITA, S., NAWATA, H. 2000. Time-specific effects of mono(n-butyl) Phthalate on the transabdominal descent of the testes in rat fetuses. BJU International, 86, 121-125. http://dx.doi.org/10.1046/j.1464410x.2000.00710.x

SHULTZ, V.D., PHILIPS, S., SAR, M., FOSTER, P.M., GAIDO, K.W. 2001 Altered gene profiles in fetal rat testes after in utero exposure to di(n-butyl) $\begin{array}{llll}\text { phthalate. Toxicological } & \text { Science, } & \text { 64, } & \text { 235-242. }\end{array}$ http://dx.doi.org.10.1093/toxsci/64.2.233

SJOBERG, P., BONDESSON, U., GRAY, T.J., PLOEN, L. 1986. Effects of di(2-ethylhexyl) phthalate and five of its metabolites on rat testis in vivo and in in vitro. Acta Pharmacologica et Toxicologica (Copenh), 58, 225-233. http://dx.doi.org/10.1111/j.1600-0773.1986.tb00098.x

TANAKA, T. 2002. Reproductive and neurobehavioral toxicity study of bis(2ethylhehyl) phthalate (DEPH) administrated to mice in the diet. Food and Chemical Toxicology, 40, 1499-1506. http://dx.doi.org/10.1016/s02786915(02)00073-x

WONG, J.S., GILL., S.S. 2002. Gene expression changes induced in mouse liver by di(2-ethylhexyl) phtalate. Toxicology and Applied Pharmacology, 185, 180196. http://dx.doi.org/10.1006/taap.2002.9540 